\title{
Molecular genetic diversity of donkey (Equus asinus) in South Korea
}

\author{
Sungwook Yun ${ }^{\mathrm{a}}$, and Giljae Cho ${ }^{\mathrm{b} *}$ \\ ${ }^{1}$ Animal and Plant Quarantine Agency, Pusan 50800, ${ }^{2}$ College of Veterinary Medicine, \\ Kyungpook National University, Daegu 41566, Korea
}

(1)

\section{Abstract}

The research on domestic donkey has little information and criteria comparing to other livestock, companion animal in South Korea. We analyzed genetic database of domestic donkey using microsatellite marker to clarify domestic donkey identification and paternity test. It is the first microsatellite marker analysis on domestic donkey in South Korea.

We studied 179 horse samples from 50 Thoroughbred, 50 Jeju Halla horse, including 79 donkeys then analyzed 15 microsatellite marker (AHT4, AHT5, ASB2, ASB17, ASB23, CA425, HMS1, HMS2, HMS3, HMS6, HMS7, HTG4, HTG10, LEX3 and VHL20). We observed genetic diversity from biostatic analysis of them.

The number of alleles on total average is 6.08 observed from 1 (ASB17), 2 (HMS1) to 14 (AHT5). The observed heterozygosity (OHet) is from 0.0000 (ASB17, HMS1) to 0.8608 (ASB23) which is mean value of 0.4861 , the expected heterozygosity (EHet) is from 0.0000 (CA425) to 0.9104 (AHT5) with mean value of 0.5915, and the Polymorphism Information Content (PIC) on each group of microsatellite marker is from 0.0000 (ASB17) to 0.8968 (AHT5) observed as a mean value of 0.5374. Among 15 markers AHT4, AHT5, ASB23, CA425, HMS2, HMS3, HTG4, HTG10, LEX3 is observed above 5.000.

The results on 15 microsatellite marker analysis of 3 horse groups is that the donkey had 0.5915 EHet, 0.4861 OHet on average, Thoroughbred had 0.6721 EHet, 0.6587 OHet on average, and the Jeju halla horse had 0.7898 EHet, 0.7093 OHet on average observed. Furthermore the mean alleles value is observed as 6.08, 4.83, 8.00 in donkey, Thoroughbred, Jeju halla horse breed in each.

Keyword : donkey, microsatellite marker, Korea. 


\section{1. Introduction}

2 Donkey is a domesticated animal belonging to Equidae along with horse and zebra. It is

3 assumed that the domestication of Equus asinus took place in $6000 \mathrm{BC}$ in North Africa

4 (Egypt area) from Nubian wild ass and Somalian wild ass [2, 21]. Donkey has worked with

5 mankind for centuries, and the most important role was transportation. Donkey still remains

6 an important work stock animal in poor territories.

7 The height of donkey's withers is very diverse depending on the species, known to be

8 average $102 \mathrm{~cm}$. The coat color, too, varies, such as white, gray and black and it has a black

9 stripe from the mane to the tail and another stripe sideways on the shoulders. The mane is

10 short and straight up, and the shape of the tail with long hairs only at the tip is closer to a cow

11 than a horse. The ears are very long and the base and tip are black. Unlike a horse, donkey's

12 chestnuts are located only on the front legs.

13 It is assumed that domestically bred donkey has been introduced from northern regions such

14 as China and Mongolia, and it is assessed that currently, in South Korea, about 800 horses of

15 donkey are bred, but the exact breed, introduction route and breeding scale are not well

16 known. According to the study of Yun [27], it was observed that in the domestically bred

17 donkey, the ear length was 17 28 cm (average $23 \mathrm{~cm}$ ); withers height, 90 135 cm (average

$18118.3 \mathrm{~cm}$ ); and body length, 109 150 cm (average $131.2 \mathrm{~cm}$ ). It was reported that the

19 distribution of coat colors was white, chestnut, gray, black and brown. The domestic feeding

20 status is that they are bred mostly in Gyeonggi-do, Jella-do, Gyeongsang-do and Gangwon-do

21 regions.

22 The purposes of breeding are mostly for experience, tourist carriage, or eating, but there are

23 no basic data for the utilization of domestically bred donkey and the preservation of the blood.

24 A DNA marker refers to short DNA fragment with polymorphism on DNA sequence that can

25 indicate the location of a specific gene on the chromosome. For various genes and DNA

26 markers involved in an economic trait, when DNA markers and these character genes are

27 located close to each other, according to the degree of genetic recombination, the basis of

28 Mendelian genetics, there are regions of the genes in which almost no gene cross occurs 
1 among them. Thus, the gene map that indicates the locations of specific DNA markers and

2 these markers is the starting point and the key tool [3].

3 Recently, in most animals like a man, the DNA analysis technique using microsatellite

4 markers has been applied to the differentiation of individual, paternity test, the preservation

5 of endangered animals, phylogenesis related to the origin and production traceability.

6 It is known that generally, DNA constitutes chromosome with functional DNA, which

7 includes genetic information and nonfunctional DNA, which does not include genetic

8 information. In the DNA, which does not include genetic information, there is a tandem

9 repeat sequence region, and the repeating unit of this region formed by the repetition of

10 sequences of 10-50 bases is called Variable Number of Tandem Repeat (VNTR) and the

11 repeating unit formed by the repetition of sequences of 2 7 bases is called Short Tandem

12 Repeat (STR) or Microsatellite [4]. Microsatellite is sized about 100 400 bp. Even in

13 severely damaged DNA specimens, it can be amplified, and gene inspection can be

14 conducted with a small amount of DNA while VNTR has a lot of allelic genes, so it is

15 difficult to measure its exact size, but microsatellite has fewer number of allelic genes than

16 VNTR, so it is possible to identify them accurately. Thus, microsatellite markers are widely

17 used for the differentiation of individuals of animals, including human or paternity test [11,

18 26].

19 Recently, in most animals like a man, the DNA analysis technique using microsatellite

20 markers has been applied to the differentiation of individual, paternity test, the preservation

21 of endangered animals, phylogenesis related to the origin and production traceability. In

22 addition, countries throughout the world have widely used microsatellite markers since the

23 mid-1990s for the purposes of the hereditary diversity of the country's traditional domestic

24 animals, origination and system, hereditary characteristics and preservation $[1,5]$.

25 Microsatellite refers to numerous repeats of simple base sequences existing in genomes of an

26 organism, which is abundantly distributed throughout the entire spinal animal genomes in

27 short, simple and repetitive base forms [12].

28 Microsatellite has a high mutation rate over $1 / 10^{4} \sim 1 / 10^{6}$ per generation and has high

29 viscosity according to the group. These characteristics show specific polymorphism at the 3 
1 object level as well as in the group, so it is used as a useful tool for genetic mapping as well

2 as information about the hereditary diversity of animals, including human and plants [8, 10,

$313,14,24]$.

4 Polymorphism of microsatellite is formed by the number of repeats of the basic repeating unit,

5 which is inherited according to Mendel's law of inheritance of a half from parents.

6 Microsatellite locus evenly distributed in chromosome DNA shows various variations

7 between individuals, so it is used for an analysis of the relationship between individual breeds

8 and as an important marker for chromosome mapping. Till now, nothing has been known

9 about the function of microsatellite, but it was reported that it is the region appearing

10 common in the genes of all vertebrates, the length of base sequence varies depending on the

11 number of repetitions, and each marker has many allelic genes. This length polymorphism is

12 inherited to offspring from the mother and father according to Mendel's law, existing in the

13 form of allelic genes on the chromosome and showing hereditary polymorphism by each

14 individual [14]. In parentage diagnosis, microsatellite and minisatellite can be used

15 simultaneously, but using microsatellite used as a standard for international genetic mapping

16 can easily secure amplified primer, observe various genotypes and check the unique

17 hereditary characteristics of the individual, so it is usefully utilized as a marker for the blood

18 registration through the differentiation of individuals and parentage diagnosis [13, 24].

19 Microsatellite in a horse was reported for the first time by Ellegren et al. [8] and Marklund et

20 al. [14].

21 It is judged that in South Korea, donkey will be in the limelight as a high-value genetic 22 resource in the future. In addition, it may be disguised as horse meat. To monitor this, it is 23 necessary to protect breeding farms through a donkey meat traceability system. This study

24 aims to secure basic data to increase the protection and utilization of genetic resources of 25 domestic donkey, getting ready for the traceability system of domestic donkey using 26 microsatellite markers and investigating the hereditary diversity of donkey. 
1 Genomic DNAs from whole blood samples of 179 horse breeds [79 donkey, 50

2 Thoroughbred and Jeju Halla horse (Thoroughbred and Jeju horse crossbred)] were extracted

3 using a MagExtractor System MFX-2000 (Toyobo, Osaka, Japan) according to the

4 manufacturer's protocols [24].

5 For the quantification of the separated DNA, the absorbance was measured at the $260 \mathrm{~nm}$ and

$6280 \mathrm{~nm}$ wavelengths using Nanodrop ${ }^{\mathrm{TM}} 8000$ Spectrophotometer (Thermo, USA), and DNA

7 extracted based on absorbance at $260 \mathrm{~nm}$ at the value of 1.0 (Path length $=10.0 \mathrm{~mm}$ ) was

8 diluted, and the concentration was adjusted to $50 \mathrm{ng} / \mathrm{ul}$. In addition, samples with too high or

9 too low A260/A280 ratio based on 1.8 purity was judged to be low, and DNA was re-

10 extracted from the blood to use in the experiment.

11 To separate and check the quantified DNA by the naked eye, the finally extracted DNA was

12 checked by electrophoresis on $2.5 \%$ Agarose at $100 \mathrm{~V}$ for $30 \mathrm{~min}$. using Mupid-2 Plus

13 Electrophoresis Cell (TaKara, Japan).

\subsection{Microsatellite markers and analysis}

16 Fifteen microsatellite markers (AHT4, AHT5, ASB2, ASB17, ASB23, CA425, HMS1,

17 HMS2, HMS3, HMS6, HMS7, HTG4, HTG10, LEX3 and VHL20) were used for analysis of

18 the horse breeds. PCR was performed according to the manufacturer's protocols. Of the 15

19 markers, with markers ASB17, ASB23, CA425, HMS1 and LEX3, a single PCR was

20 conducted. As for composition for PCR, template DNA $2 \mu \mathrm{l}, 10$ Pmol forward and reverse

21 primer 2 ul, respectively and sterile distilled water 2 ul were mixed on PCR Premix buffer

22 (Qiagen, Germany), adjusted to $15 \mu \mathrm{l}$ in total, and then, amplified by GeneAmp PCR system

239700 (Applied Biosystems, USA).

24 In the PCR process, heating at $95^{\circ} \mathrm{C}$ for $10 \mathrm{~min}$. to induce degeneration and three steps of

25 denaturation at $95^{\circ} \mathrm{C}$ for $30 \mathrm{sec}$, annealing at $60^{\circ} \mathrm{C}$ for $30 \mathrm{sec}$., and extension at $72^{\circ} \mathrm{C}$ for 60

26 sec. were repeated 30 times in total, and lastly, the final extension process was made at $72^{\circ} \mathrm{C}$

27 for $60 \mathrm{~min}$. 
1 For the single PCR, template DNA $2 \mu \mathrm{l}, 10$ Pmol forward and reverse primer $2 \mathrm{ul}$,

2 respectively and sterile distilled water 6.5 ul were mixed on PCR Premix buffer (Qiagen,

3 Germany), adjusted to $25 \mu \mathrm{l}$ in total, and then, amplified by GeneAmp PCR system 9700

4 (Applied Biosystems, USA).

5 In the PCR process, heating at $95^{\circ} \mathrm{C}$ for $5 \mathrm{~min}$. to induce degeneration and three steps of

6 denaturation at $95^{\circ} \mathrm{C}$ for $30 \mathrm{sec}$., annealing at $60^{\circ} \mathrm{C}$ for $30 \mathrm{sec}$., and extension at $72^{\circ} \mathrm{C}$ for 60

7 sec. were repeated 35 times in total, and lastly, the final extension process was made at $72^{\circ} \mathrm{C}$

8 for $60 \mathrm{~min}$.

9 With the amplified DNA, dielectrolysis was made with $2.5 \%$ agarose gel, and by comparing

10 the amplification and concentration indirectly, it was tested for genotype determination.

11 The genotype analysis after the PCR was as follows: Mixing the amplified fragment $0.5 \mathrm{ul}$,

12 Gene Scan 500 RIZ size standard (Applied Biosystems, USA) 0.25 ul and deionized Hi-Di

13 formamide (Applied Biosystems, USA) 12.25 ul well to make the final volume $13 \mathrm{ul}$;

14 denaturation at $95^{\circ} \mathrm{C}$ for three min. and dipping on ice for three min.; loading the denatured

15 PCR product on automatic gene analyzer (ABI 3130 xl Genetic Analyzer, USA); and

16 electrophoresis on POP 7 polymer (Applied Biosystems, USA) at $15 \mathrm{kV}$. Then, with the peak

17 row data, the size of allelic genes (base pair) for each marker was determined based on the

18 result of 2015/2016 Horse Comparison Test No. 1 of the International Society for Animal

19 Genetics (ISAG) using GeneMap Software ver. 4.0 (Applied Biosystems, USA).

\subsection{Statistical analysis}

22 Analysis of the hereditary diversity of domestically bred Equus asinus, that is, the observed 23 heterozygosity (OHet), expected heterozygosity (EHet), number of allelic genes and 24 frequency was conducted, using Microsatellite Marker Tool Kit Ver. 3.1.1 (Microsoft@, USA) 25 [19], and the Polymorphism Information Content (PIC) of the groups for each microsatellite 26 marker analyzed [6] was calculated through the methods of Marshall et al. [15] and Nei et al. 27 [16]. 
1 To examine the cousin relation of domestically bred Equus asinus, for the estimation of DA

2 genetic distances for an analysis of the relationships among the groups, the distances were

3 calculated, using DISPAN Package [18], a population genetics analysis program that uses the

4 method of Nei et al. [16], and using the DISPAN, a phylogenetic tree was drawn up based on

5 the hereditary distances between the groups, through Unweighted Pair-group Method With

6 Arithmetic Average (UPGMA) [22] method. Based on the estimated value of the individual

7 hereditary distances of all groups, for drawing up DA genetic distances among all individuals,

8 Phylip Ver.3.69 statistics program, a population genetics analysis program was used based on

9 the frequency of individual allelic genes through the level of simple allele-sharing

10 measurement [9].

\section{Results}

\section{3.1. Analysis of the genetic diversity of donkey}

14 As shown in Table 1, it was observed that the number of allelic genes was 1 (ASB17) and 2 15 (HMS1) to 14 (AHT5), 6.00 on average. The OHet was 0.0000 (ASB17, HMS1) to 0.8608 16 (ASB23), 0.4861 on average. The EHet was 0.0000 (CA425) to 0.9104 (AHT5), 0.5915 on 17 average; and the Polymorphism Information Content (PIC) of groups by each microsatellite 18 marker was 0.0000 (ASB17) to 0.8968 (AHT5), 0.5374 on average. Of the 15 markers, in 19 AHT4, AHT5, ASB23, CA425, HMS2, HMS3, HTG4, HTG10, LEX3, it was higher than $20 \quad 5.000$.

21 As a results of an analysis of microsatellite DNA types of donkey, Thoroughbred and Jeju 22 Halla horse, allelic genes and frequency are as shown in Table 2 and 3. As a result of an 23 analysis of 15 microsatellite markers with the three horse groups, the average Ehet and Ohet 24 were 0.5915 and 0.4861 , respectively in donkey; 0.6721 and 0.6587 in Thoroughbred; and 250.7898 and 0.7093 in Jeju Halla horse. In addition, it was observed that the average number 26 of allelic genes was 6.00, 4.83 and 8.00, respectively in donkey, Thoroughbred and Jeju Halla 27 horse.

28 Based on the result of an analysis of microsatellite markers, dendrograms of groups for the 29 standard genetic distance and the minimum genetic distance were drawn, using Unweighted 
1 Pair Group Method with Arithmetic mean (UPGMA) and Neighbor Joining (NJ) clustering

2 method, based on the genetic matrix and presented in Figure 1. To compare the dendrograms,

3 in three breeds 179 horses, donkey and Thoroughbred breed formed a clearly different group,

4 but it was observed that Jeju Halla horse formed a group, mixed with a Thoroughbred horse.

\section{4. Discussion}

6 To meet the demands of the domestic donkey market and secure better quality donkey and

7 donkey meats, most of all, it is necessary to select donkey with excellent blood and formulate

8 and enhance donkey breeding technology. However, there are considerably very insufficient

9 investigations of the breeding and genetic of donkey as compared to those of Thoroughbred,

10 Jeju horse or Jeju Halla horse in South Korea.

11 Genotype is a stable unit at the object level but becomes an unstable unit through generations.

12 In Mendel's the law of segregation, "Genotype is the combination of two allelic genes, and

13 one side of the allelic genes, only, is delivered to the next generation in the same probability,"

14 the unit stably delivered, transcending generations of the components of genotype is not

15 genotype but allelic genes [3].

16 In a shift in generations, that only one of the allelic genes is delivered at the same probability

17 means that, since individual's genotype is the combination of two allelic genes, the

18 probability at which one allelic gene is delivered is $1 / 2$. At the chromosome level, allelic

19 genes are part of chromosome phase on one side, and in Molecular Biology, it is

20 polymorphism such as SNP and VNTR on one chromosome. For example, in SNP, allelic

21 gene becomes one side of the base of $\mathrm{T}$ or $\mathrm{C}[3,23]$.

22 As compared to genotype frequency, gene frequency is very stable beyond the generation, so

23 usually, many studies of molecular evolution deal with changes in gene frequency. However,

24 what is directly related to the phenotype of individual is genotype [7, 20].

25 As a results of an analysis of genotype distribution using microsatellite DNA markers with

26 domestically bred donkey to understand hereditary characteristics and a study to secure

27 baseline data for the protection of donkey's unique genetic resources and the promotion of

28 high value added donkey, it was observed that the average EHet and OHet were 0.5915,

29 0.4861, respectively in domestically bred donkey; 0.6721, 0.6587 in Thoroughbred; 0.7898, 
10.7093 in Jeju Halla horse. Also, it was observed that the average number of allelic genes was

2 6.00, 4.83 and 8.00 in donkey, Thoroughbred and Jeju Halla horse, respectively. It was noted

3 that Equus asinus or Thoroughbred was fixed into a single breed. However, it is assumed that

4 Jeju Halla horse had high OHet, EHet and number of allelic genes because they are cross-

5 bred horses, in which the genes of various breeds were mixed. In addition, it was observed

6 that microsatellite markers AHT4, AHT5, ASB23, CA425, HMS2, HMS3, HTG4, HTG10

7 and LEX3 were Polymorphism Information Content (PIC) over 5.000, so it is expected that

8 they can be utilized in the differentiation of individuals of Equus asinus or paternity test.

9 Based on PIC value of each marker, the validity and reliability of the marker can be estimated,

10 and if PIC value is higher than 0.5000 , it is judged that the reliability of the marker is valid

11 for blood analysis. If it is higher than 0.7000 , it is known that it has universal validity for

12 analysis and can get a result of high reliability.

13 In a single gene locus, the indicator that expresses the diversity of a group is heterozygosity.

14 Heterozygosity is defined as "the probability that, when randomly two allelic genes are

15 extracted from a group, the two may differ." In an association analysis or linkage

16 disequilibrium analysis, to be used as a marker, the higher the heterozygosity, the more

17 desirable it becomes [10, 21, 25]. Even when the plural groups are mixed, of course,

18 heterozygosity increases, but if there is no mix of groups, generally, heterozygosity is related

19 to mutation. The higher the mutation rate and the higher the effective size of the group, the

20 greater the heterozygosity (the diversity of the group) becomes [17].

21 In general, in an analysis of genetic characteristics using a microsatellite marker,

22 heterozygosity can be judged from the basic figure by which the degree of mixing of the

23 target varieties and other varieties are predicted. In general, if pure blood is preserved through

24 powerful selection without a mix of species from the outside, the value of heterozygosity

25 appears low, and if there is a mix of different breeds, it is observed that the value of

26 heterozygosity is high. However, since the value of heterozygosity becomes higher as there

27 are more individuals used in the study, it is difficult to judge the mix of species only based on

28 the value of heterozygosity. As a result of an analysis of three horse groups with 15

29 microsatellite markers, it was observed that the average EHet and OHet were 0.5915 and 
10.4861 in donkey; 0.6721 and 0.6587 in Thoroughbred; and 0.7898 and 0.7093 in Jeju Halla

2 horse. In addition, as a result of drawing up and analyzing a dendrogram of groups about the

3 standard genetic distance and minimum genetic distance, in three breeds, 179 horses, donkey

4 and Thoroughbred breed formed a clearly different group, but it was observed that Jeju Halla

5 horse formed a group, mixed with Thoroughbred horse. Heterozygosity of domestically bred

6 donkey was lower than two species and formed a group clearly differentiated like

7 Thoroughbred horse. It is assumed that heterozygosity is low because of few breeding heads

8 of domestically bred donkey and inbreeding by limited male horses.

\subsection{Conclusion}

11 We analyzed the first genetic database of domestic donkey using microsatellite marker to 12 clarify domestic donkey identification and paternity test in South Korea. The donkey was 13 observed that the number of allelic genes was 1 (ASB17) and 2 (HMS1) to 14 (AHT5), 6.00 14 on average. The OHet was 0.0000 (ASB17, HMS1) to 0.8608 (ASB23), 0.4861 on average. 15 The EHet was 0.0000 (CA425) to 0.9104 (AHT5), 0.5915 on average. The PIC of groups by 16 each microsatellite marker was 0.0000 (ASB17) to 0.8968 (AHT5), 0.5374 on average, and 9 17 microsatellite markers (AHT4, AHT5, ASB23, CA425, HMS2, HMS3, HTG4, HTG10 and 18 LEX3) were higher than 5.000. These markers are useful

\section{Acknowledgement}

21 This study was supported by Korea Institute of Planning and Evaluation for Technology in

22 Food, Agriculture, Forestry and Fisheries in the field of business of technique in Agriculture

23 and Bio industry (Project number: 316026).

24 We would like to thank Cho Cangyeon, Animal Genetic Resources Research Center, National

25 Institute of Animal Science Rural Development Administration, Republic of Korea, for his

26 comments on the Statistical analysis.

\section{References}

29 [1] Arranz JJ, Bayon Y, Primitivo FS. Comparison of protein markers and microsatellites in differentiation of cattle populations. Anim Genet 1996; 27: 415-419. 
1 [2] Beja-Pereira A, England PR, Ferrand N, Jordana S. African origins of the domestic donkey. Science 2004; 304: 1781.

3 [3] Bertorelle G, Bruford MW, Chemini C, Hauffe HC., Vernesi C. Population Genetics for $4 \quad$ Animal Conservation. Cambridge University Press; 2009.

5 [4] Binns M, Swinburne JE, Breen M. The genetics of the horse. In: Bowling AT, Ruvinsky A (ed) Molecular genetics of the horse. 2000. p. 109-121.

7 [5] Bjornstad G, Nilsen NO, Roed KH. Genetic relationship between Mongolian and $8 \quad$ Norwegian horses. Anim Genet 2003; 34: 55-58.

9 [6] Botstein D, White RL, Skolnick M, Davis RW. Construction of a genetic linkage map in 10 man using restriction fragment length polymorphisms. Am J Hum Genet 1980; 32: 314331.

[7] Dayton M, Koskinen MT, Tom BK, Mattila AM, Johnston E, Halverson J, Fantin D, DeNise S, Budowle B, Smith DG, Kanthaswamy S. 2009. Developmental validation of short tandem repeat reagent kit for forensic DNA profiling of canine biological material. Croat Med J 2009; 50: 268-285.

[8] Ellegren H, Jihansson M, Sandberg K, Andersson L. Cloning of highly polymorphic microsatellites in the horse. Anim Genet 1992; 23: 133-142.

[9] Felsenstein, J. 2007. PHYLIP-Phylogeny Inference Package. Version3.67. Department of Genetics, University of Washington. Seattle.

[10] Kang BT, Kim KS, Min MS, Chae YJ, Kang JW, Yoon J, Choi J, Seong JK, Park HC, An J, Lee MH, Park HM, Lee H. Microsatellite loci analysis for the genetic variability and the parentage test of five dog breeds in South Korea. Genes Genet System 2009; 84: 245-251.

[11] Lee HY, Park MJ, Yoo JE, Chung U, Han GR, Shin KJ. Selection of twenty-four highly informative SNP markers for human identification and paternity analysis in Koreans.

27 [12] Li K, Chen Y, Moran C, Fan B, Zhao S, Peng Z. Analysis of diversity and genetic 28 relationships between four Chinese Indigenous pig breeds and one Australian commercial 29 pig breed. Anim Genet 2000; 31: 322-325. 
1 [13] Lipinski MJ, Amigues Y, Blasi M, Broad TE, Cherbonnel C, Cho GJ, Corley S, Daftari

2 P, Delattre DR, Dileanis S, Flynn JM, Grattapaglia D, Guthrie A, Harper C, Karttunen PL,

3 Kimura H, Lewis GM, Longeri M, Meriaux JC, Morita M, Morrin-O'donnell RC, Niini T,

4 Pedersen NC, Perrotta G, Polli M, Rittler S, Schubbert R, Strillacci MG, Van Haeringen

$5 \quad$ H, Van Haeringen W, Lyons LA. An international parentage and identification panel for

6 the domestic cat (Felis catus). Anim Genet 2007; 38: 371-377.

7 [14] Marklund S, Ellegren H, Eriksson S, Sandberg K, Andersson L. Parentage testing and

8 linkage analysis in the horse using a set of highly polymorphic horse microsatellites.

9 Anim Genet 1994; 25: 19-23.

10 [15] Marshall TC, Slate J, Kruuk L, Pemberton JM. Statistical confidence for likelihood 11 based paternity inference in natural populations. Mol Ecol 1998; 7: 639-655.

12 [16] Nei M, Taima F, Tateno Y. Accuracy of estimated phylogenetic trees from molecular 13 data. J Mol Evol 1983; 19: 153-170.

14 [17] Oberbauer AM, Belanger JM, Grossman DI, Regan KR, Famula TR. Genome-wide 15 linkage scan for loci associated with epilepsy in Belgian shepherd dogs. BMC Genet 2010; $16 \quad 4: 11-35$.

17 [18] Ota T. DINPAN. Pennsylvania State University, PA. USA. 1993.

18 [19] Park, S. Microsatellite Toolkit For MS Excel 97 or 2000 (personnel communication). 192000.

20 [20] Parker HG, Kim LV, Sutter NB, Carlson S, Lorentzen TD, Malek TB, Johnson GS,

21 DeFrance HB, Ostrander EA, Kruglyak L. Genetic structure of the purebred domestic dog. 22 Science 2004; 21: 1160-1164.

23 [21] Rechi LJ. Animal Genetics. Nova Science Pub Inc. Rossel S, Marshall F, Peters J, 24 Pilgram T. 2008. Domestication of the donkey: timing, processes, and indicators. Proc 25 Natl Acad Sci USA. 2009; 105: 3715-3720.

26 [22] Saitou N, Nei M. The neighborjoining method: A new method for reconstruction phylogenetic tree. Mol Biol 1987; 4: 406-425. 
1 [23] Salim DC, Akimoto AA, Carvalho CB, Oliveira SF, Grisolia CK, Moreira JR, Klautau-

2 Guimarães MN. Genetic variability in maned wolf based on heterologous short-tandem

3 repeat markers from domestic dog. Genet Mol Res 2007; 6: 348-357.

4 [24] Tozaki T, Kakoi H, Mashima S, Hirota KI, Hasegawa T, Ishida Miura N, Choi-Miura

5 NH, Tomita M. Population study and validation of paternity testing for Thoroughbred

$6 \quad$ horses by 15 microsatellite loci. J Vet Med Sci 2001; 63: 1191-1197.

7 [25] Van de Goor LH, Panneman H, van Haeringen WA. Proposal for standardization in

8 forensic equine DNA typing: allele nomenclature for 17 equine-specific STR loci. Anim

$9 \quad$ Genet 2010; 41: 122-127.

10 [26] Werner FA, Durstewitz G, Habermann FA, Thaller G, Krämer W, Kollers S, Buitkamp J,

11 Georges M, Brem G, Mosner J, Fries R. Detection and characterization of SNPs useful

12 for identity control and parentage testing in major European dairy breeds. Anim Genet

$13 \quad 2004 ; 35: 44-49$.

14 [27] Yun SW. Molecular genetic diversity and physical characterization of donkey (Equus 
12 Table 1. Number of allele, heterozygosity, and PIC of the 15 microsatellite markers in 79 13 donkeys

\begin{tabular}{ccccc}
\hline Marker & No. of alleles & OHet & EHet & PIC \\
\hline AHT4 & 6 & 0.6076 & 0.7102 & 0.6547 \\
AHT5 & 14 & 0.8828 & 0.9104 & 0.8968 \\
ASB2 & 2 & 0.4557 & 0.4605 & 0.3529 \\
ASB17 & 1 & 0.0000 & 0.7410 & 0.0000 \\
ASB23 & 6 & 0.8608 & 0.7364 & 0.6969 \\
CA425 & 8 & 0.7722 & 0.0000 & 0.6839 \\
HMS1 & 2 & 0.0000 & 0.4154 & 0.3276 \\
HMS2 & 8 & 0.7215 & 0.7447 & 0.6989 \\
HMS3 & 6 & 0.6456 & 0.6177 & 0.5473 \\
HMS6 & 3 & 0.5063 & 0.5059 & 0.4043 \\
HMS7 & 4 & 0.2025 & 0.2320 & 0.2203 \\
HTG4 & 8 & 0.3544 & 0.7819 & 0.7461 \\
HTG10 & 8 & 0.6456 & 0.7368 & 0.7000 \\
LEX3 & 11 & 0.3671 & 0.7762 & 0.7439 \\
VHL20 & 3 & 0.3291 & 0.5041 & 0.3875 \\
Mean & 6.00 & 0.4861 & 0.5915 & 0.5374 \\
\hline
\end{tabular}


bioRxiv preprint doi: https://doi.org/10.1101/213520; this version posted November 3, 2017. The copyright holder for this preprint (which was not certified by peer review) is the author/funder, who has granted bioRxiv a license to display the preprint in perpetuity. It is made available under aCC-BY 4.0 International license.

1 *OHet : Observed heterozygosity, EHet : Expected heterozygosity, PIC : Polymorphism

2 Information Content.

3

4

5

6

7

8

9

10

11

12

13

14 
Table 2. Number of allele, heterozygosity, and PIC of the 15 microsatellite markers in 179 horse breeds

\begin{tabular}{|c|c|c|c|c|c|c|c|c|c|c|c|c|}
\hline \multirow{2}{*}{ Marker } & \multicolumn{3}{|c|}{ No. of allele } & \multirow[b]{2}{*}{ DK } & \multirow{2}{*}{$\begin{array}{c}\text { OHet } \\
\text { TB }\end{array}$} & \multirow[b]{2}{*}{ JH } & \multirow[b]{2}{*}{ DK } & \multirow{2}{*}{\begin{tabular}{|c|} 
EHet \\
TB \\
\end{tabular}} & \multirow[b]{2}{*}{ JH } & \multirow[b]{2}{*}{ DK } & \multirow{2}{*}{$\begin{array}{c}\text { PIC } \\
\text { TB }\end{array}$} & \multirow[b]{2}{*}{ JH } \\
\hline & DK & TB & $\mathbf{J H}$ & & & & & & & & & \\
\hline AHT4 & 6 & 4 & 6 & 0.6076 & 0.7800 & 0.6400 & 0.7102 & 0.6919 & 0.8081 & 0.6547 & 0.6547 & 0.7686 \\
\hline AHT5 & 14 & 5 & 7 & 0.8228 & 0.6800 & 0.7600 & 0.9104 & 0.6440 & 0.8008 & 0.8968 & 0.5882 & 0.7634 \\
\hline ASB2 & 2 & 6 & 8 & 0.4557 & 0.7600 & 0.9200 & 0.4605 & 0.8135 & 0.8121 & 0.3529 & 0.7777 & 0.7755 \\
\hline ASB17 & 1 & 5 & 13 & 0.0000 & 0.6400 & 0.7400 & 0.7410 & 0.7206 & 0.8749 & 0.0000 & 0.6675 & 0.6675 \\
\hline ASB23 & 6 & 6 & 8 & 0.8608 & 0.8000 & 0.7600 & 0.7364 & 0.7966 & 0.8208 & 0.6969 & 0.7562 & 0.7562 \\
\hline CA425 & 8 & 5 & 9 & 0.7722 & 0.5200 & 0.7400 & 0.0000 & 0.5057 & 0.7970 & 0.6839 & 0.4544 & 0.7577 \\
\hline HMS1 & 2 & 3 & 8 & 0.0000 & 0.5200 & 0.7600 & 0.4154 & 0.6317 & 0.6473 & 0.3276 & 0.5465 & 0.5742 \\
\hline HMS2 & 8 & 5 & 9 & 0.7215 & 0.3400 & 0.6200 & 0.7447 & 0.3903 & 0.7570 & 0.6989 & 0.3617 & 0.7076 \\
\hline HMS3 & 6 & 5 & 7 & 0.6456 & 0.5800 & 0.5400 & 0.6177 & 0.6519 & 0.7887 & 0.5473 & 0.5960 & 0.7501 \\
\hline HMS6 & 3 & 4 & 7 & 0.5063 & 0.6400 & 0.6400 & 0.5059 & 0.6236 & 0.7644 & 0.4043 & 0.5655 & 0.7167 \\
\hline HMS7 & 4 & 5 & 6 & 0.2025 & 0.8400 & 0.6800 & 0.2320 & 0.7697 & 0.7661 & 0.2203 & 0.7214 & 0.7189 \\
\hline HTG4 & 8 & 4 & 5 & 0.3544 & 0.5800 & 0.6600 & 0.7819 & 0.5562 & 0.6844 & 0.7461 & 0.4610 & 0.6276 \\
\hline HTG10 & 8 & 6 & 9 & 0.6456 & 0.8600 & 0.8000 & 0.7368 & 0.8158 & 0.8016 & 0.7000 & 0.7811 & 0.7648 \\
\hline LEX3 & 11 & 6 & 9 & 0.3671 & 0.6200 & 0.6600 & 0.7762 & 0.7321 & 0.8570 & 0.7439 & 0.6800 & 0.8315 \\
\hline VHL20 & 3 & 4 & 9 & 0.3291 & 0.7200 & 0.7200 & 0.5041 & 0.7380 & 0.8673 & 0.3875 & 0.6811 & 0.8427 \\
\hline Mean & 6.00 & 4.87 & 8.00 & 0.4861 & 0.6600 & 0.7100 & 0.5915 & 0.6721 & 0.7898 & 0.5374 & 0.6195 & 0.7349 \\
\hline
\end{tabular}


DK : Donkey, TB : Thoroughbred, JH : Jeju Halla horse (crossbred), OHet : Observed heterozygosity, EHet : Expected heterozygosity, PIC : Polymorphism Information Content. 
Table 3. Expected, Observed heterozygosity and mean number of alleles(MNA) observed across 15 microsatellite loci for each population

\begin{tabular}{cccccc}
\hline Population & Sample size & \pm Unbiased HzSD & \pm Obs HzSD & MNA & MNA SD \\
\hline DK & 79 & \pm 0.59150 .0624 & \pm 0.48610 .0145 & 6.00 & 3.63 \\
TB & 50 & \pm 0.67210 .0310 & \pm 0.65870 .0173 & 4.83 & 1.03 \\
JH & 50 & \pm 0.78980 .0160 & \pm 0.70930 .0166 & 8.00 & 1.89 \\
\hline
\end{tabular}

DK : Donkey, TB : Thoroughbred, JH : Jeju Halla horse (crossbred). 


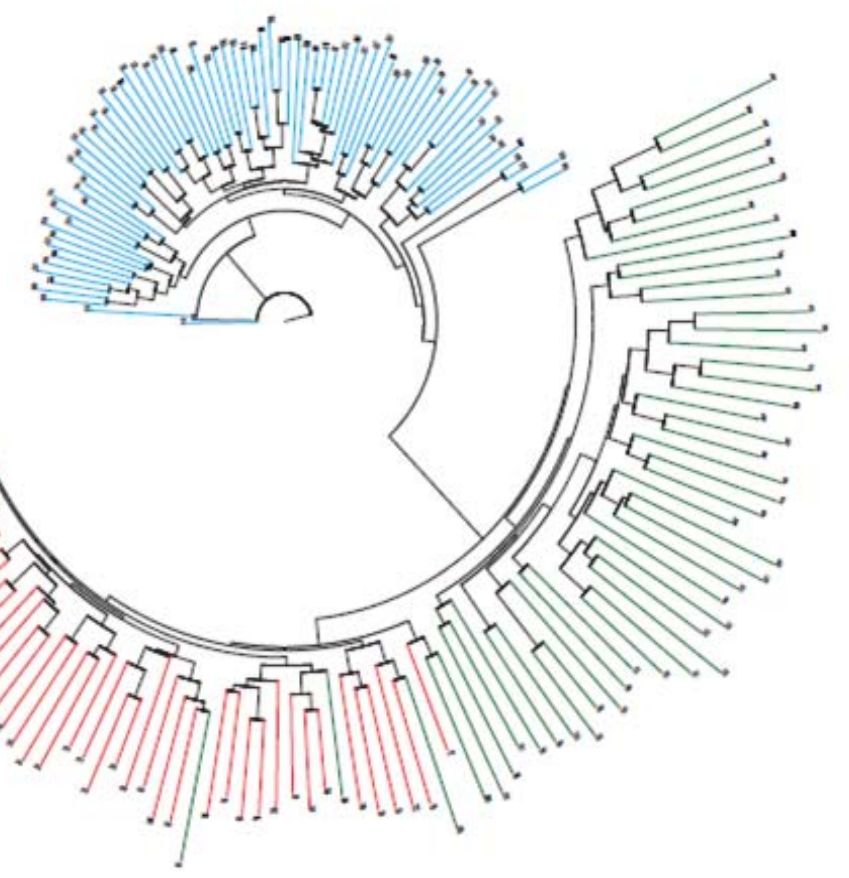

Fig. 1. Phylogenetic tree showing allele-sharing distances among 179 individuals in 1 donkey and 2 horse breeds

Blue color : donkey, Green color : Thoroughbred, Red color : Jeju Halla horse. 
bioRxiv preprint doi: https://doi.org/10.1101/213520; this version posted November 3,2017 . The copyright holder for this preprint (which was not certified by peer review) is the author/funder, who has granted bioRxiv a license to display the preprint in perpetuity. It is made available under aCC-BY 4.0 International license. 